\title{
CONSERVATÓRIOS ESTADUAIS MINEIROS: DA FORMAÇÃO DE PROFESSORES DE MÚSICA A PROJETOS, PARCERIAS E CAPACITAÇÃO DOCENTE PARA O ENSINO BÁSICO
}

Denise Coimbra Alves

Recebido em 29/06/2017

Aprovado em 10/09/2017 
Neste recorte de minha dissertação de Mestrado (Prof-Artes), sintetizo a cronologia das ações da Secretaria de Estado da Educação de Minas Gerais, que envolveram os Conservatórios Estaduais de Música, com definidos propósitos de atendimento à escolarização básica obrigatória, desde a formação de Professores de Música, seguida de projetos e parcerias. Concluo com o relato de minha participação na elaboração, implantação e como professora do Curso de Extensão em Educação Musical, em 2012, no Conservatório Estadual de Juiz de Fora, destinado à capacitação de professores estaduais não especialistas em Música, para inserção da Música no âmbito escolar em cumprimento da Lei n. 11.769/2008.

Palavras-Chave: Conservatórios de Música. Políticas públicas. Capacitação docente.

\section{INTRODUÇÃO}

$\mathrm{O}$ s 12 Conservatórios Estaduais de Música de Minas Gerais (CEM), criados também com a finalidade de formação de profissionais para o atendimento ao ensino escolar obrigatório, são atualmente classificados como escolas de nível técnico. Em sua trajetória de mais de 60 anos, a nomenclatura do curso de Professor de Música foi alterada para Educação Musical e posteriormente, Magistério de Educação Artística de $1^{\circ}$ grau.

Após a extinção do curso, por força de lei, há duas décadas, os CEM vêm desenvolvendo projetos, capacitação de docentes e parcerias para e com escolas básicas, preservando sua histórica finalidade de centros pedagógicos musicais. Em cumprimento da Lei n. 11.769/2008 (BRASIL, 2008), de inserção da Música no ensino básico e, por determinação da Secretaria de Estado de Educação (SEE/MG), implantou-se em 2012 nos 12 Conservatórios, o Curso de Extensão de Educação Musical (CEEM), tendo como objetivo prioritário a capacitação de professores estaduais.

Embora a LDBEN 9.394/96 (BRASIL, 1996) defina que a atuação na educação básica é destinada a professores de nível superior e ou de formação mínima, em nível médio, na modalidade normal, observa-se a presença de técnicos em Música como docentes (PIMENTEL, 2015). Destaque-se que, além dos 12 conservatórios, Minas Gerais, é o segundo estado brasileiro em oferecimento de cursos superiores de Música ${ }^{1}$ (ALVES, 2016).

Sob aporte de literatura, análise de documentos e relato de experiência, este artigo é um recorte de minha dissertação de Mestrado no Programa de Pós-graduação em Artes em rede (Prof-Artes), na Escola de Belas Artes da Universidade Federal de Minas Gerais (UFMG). Defendida 
em agosto de 2016, sintetiza os diferentes momentos em que as ações dos CEM representaram, junto à SEE/MG, o principal meio de inclusão da Música nas escolas estaduais do entorno de cada unidade, trazendo à luz a sua experiência como forma introdutória para o relato de meu envolvimento como colaboradora na coordenação e professora do Curso de Extensão em Educação Musical, oferecido pelo Conservatório Estadual de Música Haidée França Americano (CEMHFA), sediado no município de Juiz de Fora, Minas Gerais.

\section{BREVE HISTÓRICO SOBRE A FORMAÇÃO DE Professores de MÚsiCA PELOS CONSERVATÓRIOS Estaduais de Música de Minas Gerais}

I naugurado em 1925, o Conservatório Mineiro de Música (CMM) dá início à formação oficial de Professores de Música no Estado de Minas Gerais (REIS, 1993). Intenções de se criarem escolas semelhantes, descentralizadas da capital, são registradas no final de 1930, quando o então diretor do CMM, Levindo Furquim Lambert, elabora, juntamente com Cincinato Duque Bicalho, músico juiz-forano e Francisco de Sales de Oliveira, diretor do Banco de Crédito Real de Minas Gerais, o anteprojeto, não consumado na época, que contemplaria o município de Juiz de Fora com um Conservatório (MOTA, 2006).

A federalização do CMM, em 1950, e outras políticas da época impulsionaram a criação dos cinco primeiros Conservatórios Estaduais de Música em regiões mineiras distintas, propiciando a formação docente oficial na área musical (GONÇALVES, 1993). Lê-se no documento de criação dos Conservatórios Estaduais, assinados pelo então Governador de Minas Gerais, Juscelino Kubitschek, a implantação dos cursos:

a) Curso de Professor de Música para as cátedras de Canto Coral e Orfeão das Escolas Normais, Institutos, Orfanatos, Grupos Escolares e demais estabelecimentos de ensino do Estado; b) Curso de Canto; c) Curso de Instrumentistas, destinado à formação de músicos e executantes e virtuoses (MINAS GERAIS, 1951, s/p).

Embora o diploma de Professor de Música fosse válido para designações e concursos no magistério público mineiro (MINAS GERAIS, 1952), depoimentos colhidos por Gonçalves (1993) apontam menor valorização, por parte dos alunos, do referido curso em relação aos de Canto e Instrumentos. Foram criados, de 1951 a 1985, 22 Conservatórios Estaduais de Música. Dentre eles, 12 funcionam plenamente como escolas estaduais. O destino dos demais conservatórios requer ainda pesquisas. Pertinente, para clareza neste trabalho, a exposição da tabela ao lado elaborada por Gonçalves (1993): 
Tabela 1 - Relação dos Conservatórios Estaduais de Música criados em Minas Gerais

\begin{tabular}{|c|c|c|c|c|c|}
\hline & Localização & $\begin{array}{l}\text { Ato de } \\
\text { criação }\end{array}$ & Data & $\begin{array}{c}\text { Ato de } \\
\text { Oficialização }\end{array}$ & $\begin{array}{c}\text { Funcionamento } \\
\text { como Escola } \\
\text { Estadual }\end{array}$ \\
\hline 1 & São João Del & Lei n. 811 & $13 / 12 / 1951$ & $*$ & Março de 1953 \\
\hline 2 & $\begin{array}{c}\text { Rei } \\
\text { Uberaba }\end{array}$ & Lei n. 811 & 13/12/1951 & $\begin{array}{l}\text { Lei } \mathrm{n} . \\
1.119 \text { de }\end{array}$ & $\begin{array}{c}\text { Encampado pela } \\
\text { Lei n. } 4.556 \text { de }\end{array}$ \\
\hline $\begin{array}{l}3 \\
4\end{array}$ & $\begin{array}{l}\text { Diamantina } \\
\text { Visconde do }\end{array}$ & $\begin{array}{l}\text { Lei n. } 811 \\
\text { Lei n. } 811\end{array}$ & $\begin{array}{l}13 / 12 / 1951 \\
13 / 12 / 1951\end{array}$ & $\begin{array}{c}03 / 11 / 1954 \\
*\end{array}$ & $\begin{array}{c}06 / 09 / 1967 \\
\text { Outubro de } 1970 \\
\text { Abril de } 1953\end{array}$ \\
\hline $\begin{array}{l}5 \\
6\end{array}$ & $\begin{array}{l}\text { Rio Branco } \\
\text { Juiz de Fora } \\
\text { Pouso Alegre }\end{array}$ & $\begin{array}{l}\text { Lei n. } 811 \\
\text { Lei n. } 825\end{array}$ & $\begin{array}{l}13 / 12 / 1951 \\
14 / 12 / 1951\end{array}$ & * & $\begin{array}{l}\text { Janeiro de } 1955 \\
\text { Setembro de }\end{array}$ \\
\hline $\begin{array}{l}7 \\
8\end{array}$ & $\begin{array}{l}\text { Leopoldina } \\
\text { Montes Claros }\end{array}$ & Lei n. 1.123 & 03/11/1954 & * & $\begin{array}{c}1954 \\
\text { Janeiro de } 1956 \\
\text { Março de } 1962\end{array}$ \\
\hline 9 & $\begin{array}{l}\text { Conselheiro } \\
\text { Lafaiete }\end{array}$ & & & * & $* 2$ \\
\hline 10 & Ouro Fino & & & * & * \\
\hline 11 & Divinópolis & Lei n. 1.239 & & $*$ & $*$ \\
\hline 12 & Itaúna & & $14 / 02 / 1955$ & $*$ & $*$ \\
\hline 13 & Almenara & & & * & * \\
\hline 14 & Bom Despacho & & & $*$ & * \\
\hline 15 & Alfenas & & & * & $*$ \\
\hline $\begin{array}{l}16 \\
17\end{array}$ & $\begin{array}{l}\text { Carangola } \\
\text { Uberlândia }\end{array}$ & Lei n. 1.262 & $12 / 07 / 1955$ & $\begin{array}{c}* \\
\text { Lei } \mathrm{n} . \\
2.374 \text { de }\end{array}$ & $\begin{array}{c}* \\
\text { Encampado no } \\
\text { ano de } 1967\end{array}$ \\
\hline $\begin{array}{l}18 \\
19 \\
20 \\
21\end{array}$ & $\begin{array}{c}\text { Ituiutaba } \\
\text { Santos Dumont } \\
\text { Viçosa } \\
\text { Araguari }\end{array}$ & $\begin{array}{l}\text { Lei n. } 3.595 \\
\text { Lei n. } 3.665 \\
\text { Lei n. } 4.966 \\
\text { Decreto n. }\end{array}$ & $\begin{array}{l}25 / 11 / 1965 \\
03 / 12 / 1965 \\
07 / 10 / 1968 \\
22 / 03 / 1985\end{array}$ & $\begin{array}{c}07 / 041961 \\
* \\
* \\
* \\
*\end{array}$ & $\begin{array}{c}\text { Agosto de } 1967 \\
* \\
\text { Março de } 1985\end{array}$ \\
\hline 22 & Varginha & $\begin{array}{c}24.331 \\
\text { Decreto } \mathrm{n} . \\
24.373\end{array}$ & 22/03/1985 & $*$ & Março de 1985 \\
\hline
\end{tabular}


Embora tardiamente, adaptando-se à Lei n. 4.024/1961 (BRASIL, 1961), a nomenclatura inaugural do curso de Professor de Música, oferecido pelos CEM, foi substituída por Professor de Educação Musical (MINAS GERAIS, 1969). Diplomas com as nomenclaturas supracitadas, emitidos por essas instituições, puderam ser registrados no Ministério da Educação e Cultura até 1982 (ALVES, 2016), através da Portaria n. 723/1977 (BRASIL, 1977), equivalendo ao curso de Licenciatura em Música, através do Instituto Villa Lobos, hoje Universidade Federal do Estado do Rio de Janeiro (UniRio). A mesma portaria autorizou a emissão de registro de Professor de Disciplinas Específicas dos Cursos Técnicos de Música.

Sob a vigência da Lei n. 5.692/71 (BRASIL, 1971), o curso destinado à formação docente recebeu, nos Conservatórios Estaduais, a nomenclatura de Magistério de Educação Artística de $1^{\circ}$ grau (MEA). Por falta de demanda, o CEM de Juiz de Fora formou a última turma do referido curso em 1988 (MOTA, 2006). Entretanto, Carmo (2002) menciona plena atividade do MEA em alguns CEM até o início de 2000, embora a LDBEN n.9.394/96 (BRASIL, 1996) apontasse para a formação do professor em nível superior preferencialmente. Este último curso requer ainda pesquisas sobre seu impacto nas escolas do Estado e nos próprios CEM, no que se refere a designações de professores portadores desse diploma.

\section{CONSERVATÓRIOS:}

PROJETOS E PARCERIAS COM ESCOLAS BÁSICAS

parceria entre a SEE/MG e a Escola de Música da UFMG, envolvendo
os 12 CEM, ocorrida em 1998 e 1999, resultou no Projeto Música
na Escola (KATER, 2012; MOURA et al., 1998; MOURA, 2007). Professores da UFMG prepararam uma equipe oriunda de cada CEM que, apesar de não mais cumprirem oficialmente a função de formadores de Professores de Música, treinaram e supervisionaram alfabetizadores de escolas básicas estaduais e municipais de suas respectivas regiões. Embora suspenso na mudança de governo estadual mineiro (LOUREIRO, 2003), o projeto serviu de modelo para outros estados brasileiros (KATER, 2012).

Em decorrência dos resultados positivos do supracitado projeto e sob a nomenclatura geral de Projeto de Integração (CARMO, 2002; MOTA, 2006), seguiram-se parcerias entre os Conservatórios Estaduais e as escolas básicas, cujos projetos foram elaborados isoladamente por cada CEM, a exemplo do Projeto de Integração Música na Escola, em Pouso Alegre (BORGES, 2008), Semearte e o Conservatório na Rua, em Montes Claros (RIBEIRO, 2012), Música Cidadã em Uberlândia, Iukerê, em Diamantina, 
Música na Escola - Aprendendo e ensinando música na sala de aula, em Araguari e cidades da região, Brincarte em Ituiutaba, dentre outros ${ }^{3}$. Mota (2006) registra, em pioneira publicação sobre o CEM de Juiz de Fora, o Projeto Música na Escola Regular, que atendeu, entre 2002 a 2005, alunos de escolas públicas, além de uma escola estadual para pessoas com deficiências.

No mesmo ano da publicação da Proposta Curricular/Arte da SEE/ MG (MINAS GERAIS, 2005a), com a finalidade de orientar professores dos anos finais do ensino fundamental, a Secretaria de Governo publicou a Resolução SEE/MG n.718/2005 (MINAS GERAIS, 2005b), específica para os Conservatórios Estaduais mineiros que regulamentou, então nos CEM, a oferta de Cursos Livres destinados prioritariamente à atualização e requalificação em Música de professores do ensino básico, a manutenção de projetos existentes e criação de novos, além de parcerias com instituições de ensino básico, dentre outras atividades de caráter facultativo em atendimento à comunidade em geral.

Em 2015, orientações complementares à citada Resolução, priorizaram parcerias entre os CEM e as escolas que oferecem o Projeto de Educação em Tempo Integral (PROETI) (MINAS GERAIS, 2015), já desenvolvidas pelos CEM de Leopoldina e Araguari. Entretanto, essa parceria não se consumou no CEM de Juiz de Fora, bem como a proposta de se criar projetos destinados à orientação dos profissionais da Educação para a inclusão da Música em escolas básicas (ALVES, 2016).

\section{O Curso de Extensão de Educação Musical}

mparado por Resolução (MINAS GERAIS, 2005b) e determinação
da SEE/MG, implanta-se, compulsoriamente em 2012, o Curso
de Extensão em Educação Musical (CEEM), nos CEM, destinado a capacitar profissionais, para dar cumprimento às exigências da Lei $\mathrm{n}$. 11.769/2008 (BRASIL, 2008), de inserção da Música nas escolas, priorizando a inscrição de professores estaduais de Arte e conteúdos correlatos.

As Superintendências Regionais de Ensino (SRE) foram responsáveis pela divulgação e o oferecimento de vagas. Disponibilizaram-se, inicialmente, 60 vagas por Conservatório e, posteriormente, esse número foi ajustado conforme a demanda. O Curso teve início em caráter emergencial, no segundo semestre de 2012, com carga horária total de 120 horas, fundamentado em

\footnotetext{
3 Os resultados e longevidade desses projetos encontram-se registrados em escassa literatura e resumidas referências no site da SEE/MG, a exemplo das informações disponíveis em https://www.educacao.mg.gov.br/component/gmg/story/2005-projeto-do-conservatorio-estadual-de-musica-de-ituiutaba-leva-a-arte-para-dentro-da-escola-regular. Acesso em 23/05/2015; Disponível em https://www.educacao. mg.gov.br/component/gmg/story/1999-projetos-apresentados-na-mostra-dos-conservatorios-ressaltam-a-importancia-da-musica-na-sala-de-aula. Acesso em: 26/01/2016.
} 
quatro eixos temáticos pré-estabelecidos pela SEE/MG, a saber: I - Educação Musical: Abordagens e Concepções, II - Elementos Musicais, III - Apreciação Musical, IV - Recursos e Tecnologias Aplicadas (CONSERVATÓRIO ESTADUAL DE MÚSICA HAIDÉE FRANÇA AMERICANO, 2013). A partir de 2015, a SEE/MG facultou a cada CEM, a descontinuidade do Curso, na ausência de demanda (MINAS GERAIS, 2015).

\section{CONSERVATÓRIOS:}

\section{PROJETOS E PARCERIAS COM ESCOLAS BÁSICAS}

S eguindo critérios estabelecidos para a escolha de representantes ${ }^{4}$, participei da reunião de implantação do CEEM, em Belo Horizonte, colaborando com a coordenação do curso no CEM de Juiz de Fora, além de assumir as aulas de: I-Educação Musical: abordagens e concepções; III-Apreciação Musical. A equipe responsável pelo Curso entendeu que não poderiam ser tomados, como base, somente a experiência adquirida nos Projetos: Música na Escola e Música na Escola Regular, pelo fato de estes se destinarem, exclusivamente, aos anos iniciais do ensino fundamental, em contextos e épocas distintas.

Requeria-se mais do que agilidade, criticidade e reflexão, para que se pudesse atender imediatamente a interesses heterogêneos e necessidades da turma de professores-cursistas. Para tanto, buscou-se sintetizar o conteúdo histórico, no que diz respeito à legislação e às políticas públicas sobre Educação Musical, visando aplicar, o mais breve possível, os princípios pedagógicos de educadores musicais que compõem a literatura especializada, sem se prolongar em teorias. Fundamentado em Schafer (1991; 2009), na Proposta Curricular/Arte da SEE/MG (MINAS GERAIS, 2005a) e na Reorientação curricular do $1^{\circ}$ ao $9^{\circ}$ ano (GOIÁS, 2009), buscou-se metodologias aplicáveis simultaneamente ao aprendizado dos professorescursistas e às suas respectivas classes de alunos. Utilizou-se inicialmente, como suporte didático, publicações, como exemplo, Descobrindo a Música (KRIEGER, 2012).

A utilização de tecnologias tornou-se imprescindível para a dinamização do Curso. Parte considerável do conteúdo das aulas foi disponibilizada eletronicamente. Áudios e vídeos de História da Música e Apreciação Musical visaram ampliar a concepção sobre aulas de Música, instigando reflexões e debates quanto à realidade contemporânea e, 
especialmente, a realidade profissional de cada cursando. Performances de professores e de alunos do CEMHFA, seguidas de explanação, serviram para os mesmos propósitos, além de contemplação artística.

A diversidade de interesses e necessidades dos professores dos níveis fundamental e médio da educação básica e, posteriormente, os de educação infantil, modificaram a dinâmica do Curso. Inexistência de demanda foi a principal causa da interrupção do CEEM, em 2016 cujos resultados estão expostos na tabela a seguir:

Tabela 2 - Escolas e professores inscritos entre o $2^{\circ}$ semestre de 2012 ao $2^{\circ}$ semestre 2015

\begin{tabular}{l|c|c}
\hline \multicolumn{1}{c|}{ MODALIDADE DA ESCOLA } & NÚMERO DE & PROFESSORES- \\
ESCOLAS & CURSISTAS \\
\hline Escolas Estaduais do município de Juiz de Fora & 39 & 145 \\
Escolas Municipais de Juiz de Fora & 10 & 16 \\
Escolas Estaduais e Municipais de outros Municípios & 8 & 11 \\
Creches Comunitárias de Juiz de Fora & 5 & 18 \\
Escolas Particulares de Juiz de Fora & 5 & 3 \\
Escolas de Música & 3 & 10 \\
Outros Estabelecimentos & 5 & 19 \\
Não informaram instituições & $\mathbf{7 5}$ & $\mathbf{2 3 0}$ \\
Total &
\end{tabular}

Fonte: Elaborada pelo autor.

Embora pesquisadores recomendem a capacitação e formação continuada de professores para suprir as necessidades (FIGUEIREDO, 2013), no Conservatório de Juiz de Fora a capacitação foi considerada por alguns como uma desvalorização do Professor de Música, colocando em dúvida a eficácia do curso de curta duração e os paradigmas pedagógicos adotados.

Considero, entretanto, que a troca de experiência, entre todos os participantes do CEEM, contribuiu sobremaneira para a compreensão da complexidade da abordagem musical, especialmente em ambientes de trabalho diferentes dos especificamente voltados para o ensino de Música. Segundo Fonterrada (2005), [...] "os professores de diversas áreas do saber podem exercer um papel diferenciado nessa tarefa, colaborando para abrir espaço à Música" (FONTERRADA, 2005, p. 289). A autora alerta quanto à necessidade de se preparar esses professores, diante da iminência de lei federal que obrigaria o ensino de Música na escola. Propõe também que o processo educacional seja predominantemente em rede, tendo em conta a necessidade de se buscar metodologias adequadas a realidades distintas (FONTERRADA, 1997).

Pela lei, cabe aos unidocentes, assumirem a educação infantil e anos iniciais do ensino fundamental. Em razão disto, Bellochio (2015) e 
outros pesquisadores defendem consistente formação em Música desses professores. Já nos anos finais do ensino fundamental e do ensino médio, na ausência de especialistas, a mesma lei permite que a função possa ser exercida por outros de áreas afins, em caráter provisório.

Em mais de 40 anos, primeiramente como aluna e posteriormente como professora do CEMHFA, tenho observado que a recomposição do quadro de professores segue também o mesmo critério legal, de admissão de profissionais ainda em formação ou, apenas, com o curso técnico em Música. Esses professores adquiriram estabilidade profissional entre 2008 e 2015, como também, considerável parcela dos inscritos no CEEM, por força da Lei Complementar n. 100/2007 (MINAS GERAIS, 2007), de efetivação de servidores públicos por tempo de serviço.

Tendo como referência Pereira (2014), cuja tese de doutorado detecta o habitus conservatorial nos currículos dos cursos de licenciatura em Música ${ }^{5}$, observa-se ainda a preferência dos licenciados em Música por escolas ou projetos específicos de Música; entre os acadêmicos, o bacharelado em Música consta como primeira opção (SOARES; SCHAMBECK; FIGUEIREDO, 2014). O amplo oferecimento de licenciaturas específicas em instrumento (BRASIL, 2004) e a prioridade dessa formação na classificação de professores para os Conservatórios têm influenciado escolhas profissionais.

Reforçando tendências conservatoriais, a SEE/MG realizou concurso em 2015, disponibilizando 1.362 vagas de professores para os 12 conservatórios, em contraposição a 826 vagas de professores de Arte, distribuídas entre as 3.686 escolas básicas estaduais (ALVES, 2016).

\section{Considerações Finais}

O envolvimento, como professora do Curso de Extensão em Educação Musical ministrado no CEMHFA, motivou meu ingresso no Mestrado, propiciando o aprofundamento na busca por respostas que fundamentassem a atribuição de os CEM capacitarem professores estaduais em Música. Representando os Conservatórios Estaduais, participei em 2013, dos debates promovidos pela Secretaria de Educação de Juiz de Fora sobre a inserção da Música na educação básica e do fórum, acerca da Base Nacional Comum Curricular (BNCC), realizado em 2015, em Brasília, pela Associação Brasileira de Educação Musical - ABEM.

5 Diferente do Modelo conservatorial, relacionado às instituições específicas de Música, o Habitus conservatorial consiste em manter no currículo de licenciatura em Música, disciplinas e abordagens próprias de cursos específicos em Música, desconsiderando peculiaridades do contexto escolar do ensino básico (PEREIRA, 2014). 
Resguardadas as peculiaridades de cada CEM, observa-se o comprometimento permanente destes junto à educação básica e sua relevância na formação inicial de professores de Música em suas respectivas regiões. Entretanto, carece de análise o desdobramento das ações e os resultados obtidos nos 12 Conservatórios, como, por exemplo, o Projeto Música na Escola. Cada CEM ainda reserva para si e seu entorno experiências que precisam ser partilhadas, no intuito de subsidiar e enriquecer a pesquisa e literatura sobre Educação Musical em Minas Gerais.

Pelo fato de Minas Gerais contar com expressivo número de conservatórios públicos e de estabelecimentos de ensino superior de Música, penso que o fortalecimento das relações entre essas entidades possa contribuir de forma efetiva para a inserção da Música na educação básica. Que ações, a exemplo do Curso de Extensão em Educação Musical - CEEM, sejam elementos de investigação e elo para que reflexões e práticas não se percam; que o CEEM não se torne mais um empreendimento relegado ao esquecimento. 


\section{REFERÊNCIAS}

ALVES, D. C. Conservatório Estadual de Música de Juiz de Fora: história e políticas atuais de capacitação de professores. 2016. 177f. (Mestrado em Artes) - Universidade Federal de Minas Gerais. Belo Horizonte, 2016.

BELLOCHIO, C. R. Educação musical e Pedagogia: mapeamento em Anais da ABEM (2001-2011). In: CONGRESSO NACIONAL DA ABEM, 22., 2015, Natal. Anais... Natal: ABEM, 2015.

BORGES, A. H.. Projetos de Integração "Música na Escola": situando o ensino musical básico no Estado de Minas Gerais. Encontro Nacional da ABEM, XVII, 2008. São Paulo. Anais... São Paulo: ABEM, 2008.

BRASIL. Lei n. 4.024, de 20 de dezembro de 1961. Fixa as Diretrizes e Bases da Educação Nacional. Brasília: MEC, 1961.

LEI No 5.692, DE 11 de agosto de 1971. Fixa Diretrizes e Bases para o ensino de $1^{\circ}$ e $2^{\circ}$ graus, e dá outras providências. Brasília: MEC, 1971.

. Ministério da Educação e Cultura. Federação das Escolas Isoladas do Estado do Rio de Janeiro. Boletim n. 049. Portaria n. 723. Autorização para emitir registros de Professor de Educação Musical e Professor de disciplinas específicas dos Cursos Técnicos de Música. Brasília: MEC, 1977. Disponível em http:// urca.unirio.br/Conteudo/Reitoria/docs/PDFBoletins1977/Bol4977.pdf. Acesso em 23/05/2016.

. Casa Civil. Subchefia de Assuntos Jurídicos. Lei n. 9.394, de 20 de dezembro de 1996. Estabelece as diretrizes e bases da educação nacional. Brasília: Casa Civil, 1996.

. Conselho Nacional de Educação, Câmara de Educação Superior. Resolução No 2, de 8 de Março de 2004 (Resolução CNE/CES 2/2004). Aprova as Diretrizes Curriculares Nacionais do Curso de Graduação em Música e dá outras providências. Diário Oficial da União, Brasília, 12 de março de 2004, Seção 1, p. 10.

. Casa Civil. Subchefia de Assuntos Jurídicos. Lei n. 11.769 de 18 de agosto de 2008. Altera a Lei n. 9394/96, para dispor sobre a obrigatoriedade do ensino de música na educação básica. Brasília: Casa Civil, 2008.

CARMO, S. R. do. (Org.). Conservatórios de Música: Arte e emoção como aliados da educação em Minas. Belo Horizonte, Lições de Minas, 2002. 
CONSERVATÓRIO ESTADUAL DE MÚSICA HAIDÉE FRANÇA AMERICANO. Plano de Curso de Extensão em Educação Musical (CEEM). Juiz de Fora/MG, 2013.

FIGUEIREDO, S. Currículo escolar e educação musical: uma análise das possibilidades e desafios para o ensino de música na escola brasileira na contemporaneidade. InterMeio: revista do Programa de Pós-Graduação em Educação, Campo Grande,v.19, n 37, p. 29-52, jan/jun. 2013.

FONTERRADA, M. A linha e a rede, 1997. O ensino de música diante de novos paradigmas. In: SIMPÓSIO PARANAENSE DE EDUCAÇÃO MUSICAL/ENCONTRO REGIONAL SUL ABEM, 1./6., 1997, Londrina. Anais... Londrina: ABEM, 1997. p.7-17.

. De tramas e fios: um ensaio sobre música e educação. São Paulo: UNESP, 2005.

GOIÁS. Secretaria de Estado da Educação. Reorientação curricular do $1^{\circ}$ ao $9^{\circ}$ ano: currículo em debate. Sequências didáticas: convite à ação: música. Goiânia: Poligráfica, 2009.

GONÇALVES, L. N. Educar pela música: Um estudo sobre a criação e as concepções pedagógico-musicais dos Conservatórios Estaduais Mineiros na década de 50. 1993. 179f. Dissertação (Mestrado em Música) - Universidade Federal do Rio Grande do Sul. Porto Alegre, 1993.

GRINGS, A. F. S. Professores do Brasil: motivações e aspirações profissionais. 2015. 180f. Tese (Doutorado em Música) - Universidade Federal do Rio Grande do Sul. Porto Alegre, 2015.

KATER, C. Por que música na escola?: algumas reflexões. In: JORDÃO, Gisele et al (Coords.). A Música na Escola. São Paulo: Allucci e Associados Comunicações, 2012. p. 42-45 Disponível em http://www.amusicanaescola. com.br/o-projeto.html. Acesso em 25/05/2014.

KRIEGER, E. Descobrindo a Música: ideias para a sala de aula. Porto Alegre: Sulina, 2012.

LOUREIRO, A. M. A. O ensino de música na escola fundamental. $4^{\mathrm{a}}$ Edição. Campinas/SP: Papirus, 2003.

MINAS GERAIS. Lei 811, de 13 de dezembro de 1951. Cria cinco Conservatórios Estaduais de Música. Belo Horizonte: Assembleia Legislativa, 1951. 
Decreto 3.870, de 08 de setembro de 1952. Aprova o regulamento dos Conservatórios Estaduais de Música. Belo Horizonte: Assembleia Legislativa, 1952.

. Decreto 11.600, de 14 de janeiro de 1969. Aprova o regulamento dos Conservatórios Estaduais de Música. Belo Horizonte: Assembleia Legislativa, 1969.

- Secretaria de Estado de Educação. Proposta Curricular Conteúdo Básico Comum (CBC): Arte. Belo Horizonte: SEE, 2005a. Disponível em http://crv.sistti.com.br/sistema_crv_dotnet/banco_objetos_ crv/\%7B81BD08C9-B1A8-46F3-BBE4-CC9C6E0F6319\%7D_propostacurricular_arte_ef.pdf. Acesso em 20/02/2016.

. Secretaria do Estado de Educação. Resolução n. 718, de 18 de novembro de 2005. Dispõe sobre a organização e o funcionamento do ensino de música nos Conservatórios Estaduais de Música e dá outras providências. Belo Horizonte: SEE, 2005b.

. Lei Complementar n. 100, de 05 de novembro de 2007. Institui a Unidade de Gestão Previdenciária Integrada - Ugeprevi - do Regime Próprio de Previdência dos Servidores Públicos do Estado de Minas Gerais e do Regime Próprio de Previdência dos Militares do Estado de Minas Gerais e o Conselho Estadual de Previdência - Ceprev -, altera a Lei Complementar ${ }^{\circ} 64$, de 25 de março de 2002 e dá outras providências. Belo Horizonte, 2007.

. Secretaria de Estado de Educação. Orientação aos Conservatórios Estaduais de Música. A Superintendência de Desenvolvimento da Educação Profissional e Diretoria de Projetos Especiais Orientam às Superintendências Regionais de Ensino e aos Conservatórios Estaduais de Música sobre a organização e o funcionamento das ações pedagógicas desenvolvidas em 2015a. Belo Horizonte: SEE, 2015.

MOTA, B. M. A. Retrospectiva histórica do Conservatório Estadual de Música "Haidée França Americano". Juiz de Fora/MG: FUNALFA, 2006.

MOURA, J. A. et al. Projeto Música na Escola: proposta para a implantação do ensino de música nas escolas da rede pública do Estado de Minas Gerais. In: ABEM. Fundamentos da Educação Musical. Série 4. Salvador: ABEM, Out./1998. p.102-105.

MOURA, J. A. Projeto Música na Escola: 1997 a 1999. In: OLIVEIRA, A.; CAJAZEIRA, R. (Org.). Educação Musical no Brasil. Salvador: P\&A, 2007. p.178-180. 
PEREIRA, M. V. M. Licenciatura em música e habitus conservatorial: analisando o currículo. Revista da ABEM, Londrina, v.22, n. 32, p. 90-103, 2014.

PIMENTEL, M. O. Q. Traços de percursos de inserção profissional: um estudo sobre egressos dos Conservatórios Estaduais de Música de Minas Gerais. 2015. 185f. Dissertação (Mestrado em Artes) - Universidade Federal do Rio Grande do Sul. Porto Alegre, 2015.

REIS, S. L. F. Escola de Música da UFMG: um estudo histórico (19251970). Belo Horizonte: Ed. Luzazul/Ed. Santa Edwiges, 1993.

RIBEIRO, M. O. O projeto conservatório na rua na perspectiva de alunos de $4^{\circ}$ e $5^{\circ}$ anos de uma escola pública de Montes Claros (MG). 2012. 121p. Dissertação (Mestrado em Música) - Universidade de Brasília. Brasília, 2012.

SCHAFER, R. M. O Ouvido Pensante. São Paulo: Fundação Editora da UNESP, 1991.

. R.M. Educação Sonora: 100 exercícios de escuta e criação de sons. São Paulo: Editora Melhoramentos, 2009.

SOARES, J.; SCHAMBECK, R. F.; FIGUEIREDO, S. O projeto de pesquisa "A formação do professor de música no Brasil". In: SOARES, J.; SCHAMBECK, R. F.; FIGUEIREDO, S. (Org.). A formação do professor de música no Brasil. Belo Horizonte: Fino Traço, 2014. p. 33-63. 